\title{
Vamos comprar ingressos: análise dos aspectos de acessibilidade para cegos em sites de venda de ingressos.
} Let's buy tickets: analysis of accessibility aspects for the blind people in ticket sale sites.

\author{
Diego Normandi \& André Schlemmer
}

interação humana-computador, acessibilidade digital, compra online, deficiência visual

\begin{abstract}
Dentre os mais de 45 milhões de residentes no Brasil com alguma deficiência, as pessoas com deficiência visual são as que compõem o maior número. É uma considerável parcela da população que enfrenta barreiras para ter acesso às informações e experiências cotidianas, caracterizadas sobretudo pelos estímulos visuais. Neste sentido, se considera que as manifestações de entretenimento e cultura disponíveis precisam possibilitar o acesso desse público em todas as fases que estruturam a jornada do usuário. Uma etapa importante nessa experiência é a aquisição de ingressos, que, hoje em dia, tem sido facilitada pela disponibilidade de sites dedicados às vendas online. Questionamos, então, se tais ferramentas que, sem dúvida, amenizam a vida dos videntes também promovem benefício para as pessoas cegas. Assim, aferimos neste artigo, por meio de sistemas de avaliação de acessibilidade digital e de ensaio de acessibilidade com três usuários reais, se quatro importantes canais de vendas online de ingressos nacionais são acessíveis e permitem aos usuários cegos utilizá-los com autonomia, segurança e eficiência.
\end{abstract}

\section{human-computer interaction, digital accessibility, online shopping, visual disability}

Among the more than 45 million residents with a disability in Brazil, disabled visual people are the ones that make up the largest number. It is a considerable part of the population that faces barriers to access to information and daily experiences, characterized mainly by visual stimuli. In this sense, it is considered that the available manifestations of entertainment and culture must allow access to this public in all the phases that structure the user's journey. An important step in this experience is the acquisition of tickets, which, nowadays, has been facilitated by the availability of sites dedicated to online sales. We quest, then, if such tools that undoubtedly soften the lives of the sighted people also promote a benefit for the blind ones.

Thus, we analyze in this article, by means digital accessibility assessment systems and by the accessibility test method with three real users, if four important online ticket sales channels are accessible and allow blind users to use them with autonomy, security, and efficiency.

\section{Introdução}

Segundo dados do IBGE, vivem no Brasil aproximadamente 45 milhões de pessoas com alguma deficiência (Censo Demográfico, 2011). Dentre este universo, os deficientes visuais são os que abrangem o maior número, ultrapassando 30 milhões de habitantes (Figura 1). Ainda que representem quantidade relevante da população nacional, é fácil perceber a quantidade de barreiras que esse público enfrenta cotidianamente, haja vista participarem de uma sociedade que tem nos estímulos visuais ${ }^{1}$ um dos principais canais de interação comunicacional. Dentre as barreiras que enfrentam, destacamos aqui as que envolvem o consumo de entretenimento cultural, uma vez que é notória a dependência da visão no acesso aos estímulos que integram esse tipo de experiência. Este artigo integra pesquisa de Doutorado que aborda a inclusão de pessoas com deficiência ao serviço de cinema, se utilizando do Design de Serviços como instrumento capaz de investigar e propor soluções a fim de se projetar um modelo de cinema

\footnotetext{
${ }^{1}$ Newton Kara José (2006) afirma que 85\% dos estímulos informacionais são transmitidos por meio da visão.

Anais do 9 CIDI e 9 CONGIC

Luciane Maria Fadel, Carla Spinillo, Anderson Horta,

Cristina Portugal (orgs.)

Sociedade Brasileira de Design da Informação - SBDI

Belo Horizonte | Brasil | 2019

ISBN 978-85-212-1728-2

Proceedings of the 9th CIDI and 9th CONGIC

Luciane Maria Fadel, Carla Spinillo, Anderson Horta, Cristina Portugal (orgs.)

Sociedade Brasileira de Design da Informação - SBDI Belo Horizonte | Brazil | 2019

ISBN 978-85-212-1728-2
} 
inclusivo². Neste momento, contudo, se delimita o público de interesse - os cegos - e a jornada do usuário - no momento de compra de ingressos online ${ }^{3}$.

Figura 1: Proporção da população brasileira com deficiência visual e outras deficiências. Fonte: Instituto Brasileiro de Geografia e Estatística - Censo Demográfico 2010.

População residente por tipo de deficiência

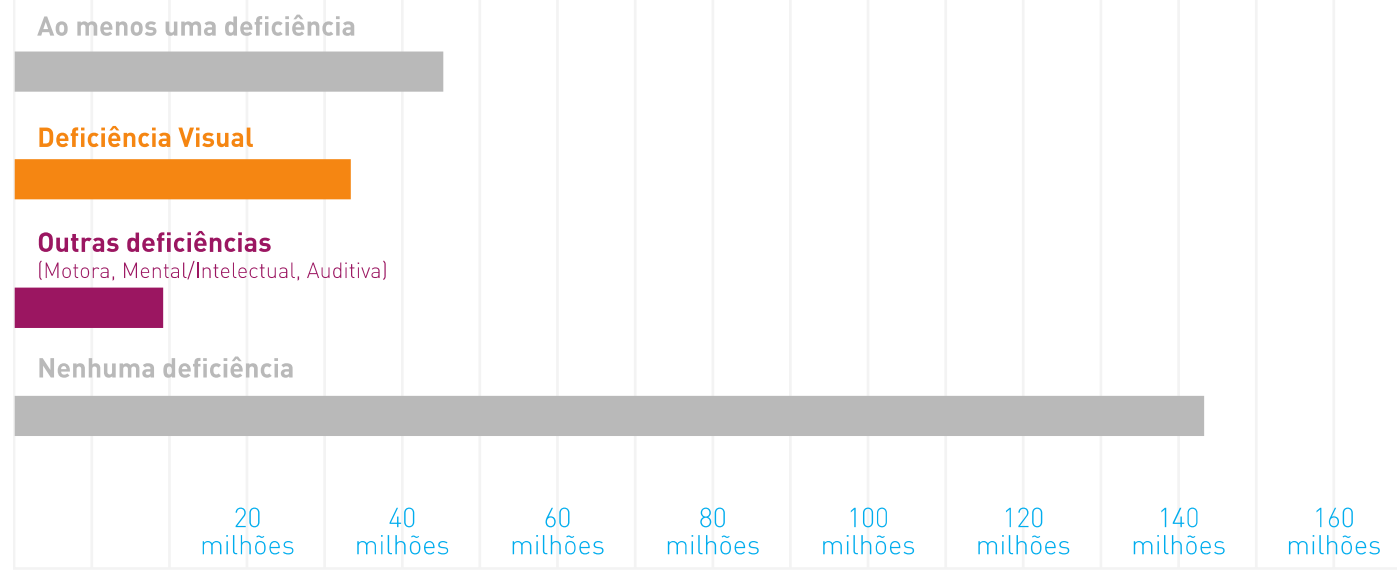

A Lei Brasileira da Inclusão - LBI define acessibilidade como "possibilidade e condição de alcance para utilização, com segurança e autonomia" inclusive em sistemas e tecnologias digitais (Brasil, 2019). Para usuários cegos, mesmo com Tecnologias Assistivas ${ }^{4}$, que promovem sua interação com os sites, se constata que seu acesso e inclusão digital ainda é caracterizada pela presença de barreiras. Segundo Cybis, Betiol e Faust (2015, p. 405) "a ausência de declarações no código HTML sobre as associações entre elementos impede que um leitor de tela faça uma leitura de melhor qualidade", portanto, a associação do código HTML em rótulos, campos, cabeçalhos, entre outros são ações primordiais para a acessibilidade digital de cegos. Entretanto, procedimentos de ensaios de acessibilidade indicam que há botões não etiquetados adequadamente, dificultando e/ou impossibilitando a interação de cegos com esses sistemas (ver Figura 6). Assim, a acessibilidade digital está vinculada com a estrutura realizada na arquitetura da informação - questões que envolvem acesso, navegação e organização do conteúdo (Cusin \& Vidotti, 2009; Marsico \& Levialdi, 2004). A revolução 4.0 foi incorporada em vários segmentos da sociedade, entre eles: os serviços. O que era físico, e fazia parte do espaço construído, foi transformado para o digital (Schwab, 2016), mas será que a transformação digital comporta o acesso para todos? Diante deste questionamento, se propõe a avaliação de serviços prestados na compra de ingressos online, focado na interação com usuários cegos.

\footnotetext{
${ }^{2}$ Entendemos como inclusivo o modelo que permite a fruição de pessoas com diferentes condições sensoriais e motoras ao acesso à experiência no mesmo ambiente e momento, mesmo que com a utilização de instrumentos e/ou serviços adaptados.

${ }^{3} \mathrm{Na}$ pesquisa de Doutorado citada se considera apenas a compra de ingressos para filmes no cinema. Neste trabalho, contudo, se avalia sites destinados a outras atividades culturais, tais como shows, teatros e também incluímos sessões cinematográficas.

4 "Refere-se a todo e qualquer item, equipamento, produto ou sistema que contribua com o desenvolvimento das potencialidades de indivíduos com limitações físicas, sensoriais, cognitivas, motoras, dentre outras restrições ou disfunções que caracterizam uma deficiência ou incapacidade de qualquer natureza" (Vivarta, 2003, p.25).
} 


\section{Acessibilidade digital}

A Lei Brasileira de Inclusão da Pessoa com Deficiência define acessibilidade como "possibilidade e condição de alcance para utilização, com segurança e autonomia" inclusive em sistemas e tecnologias (Brasil, 2019). De acordo com a mesma lei, para fins de aplicação, "qualquer entrave, obstáculo, atitude ou comportamento que dificulte ou impossibilite a expressão ou o recebimento de mensagens e de informações por intermédio de sistemas de comunicação e de tecnologia da informação" é considerado como barreiras nas comunicações e na informação (Brasil, 2019).

Por intermédio da lei, entendemos que a acessibilidade digital precisa oferecer uma navegação autônoma e apresentar ferramentas que garantam segurança e autonomia. A CAT ${ }^{5}$ (2007) conceitua "produtos, recursos, metodologias, estratégias, práticas e serviços que objetivam promover a funcionalidade, relacionada à atividade e participação, de pessoas com deficiência, incapacidades ou mobilidade reduzida, visando sua autonomia, independência, qualidade de vida e inclusão social" como Tecnologia Assistiva (TA).

Para pessoas sem deficiência, as Tecnologias Assistivas (TA's) podem ser entendidas como ferramentas que facilitam sua interação com dispositivos (tal como leitores de tela), ao passo que, para pessoas com deficiência, as TA's, mais do que facilitar, Ihes permitem acesso e inclusão. Algumas funções são essenciais para atender essas necessidades, tais como, leitor de tela, clique visual, comandado por voz, contraste, controle do tamanho da fonte, acesso a LIBRAS $^{6}$ entre outros. Alguns exemplos são apresentados a seguir.

Figura 2: Exemplos de tecnologias assistivas em sites. Fonte: A - INDCP (2019) | B - Magazineluiza (2019) | C Voeazul (2019) | D - Celepar (2019)
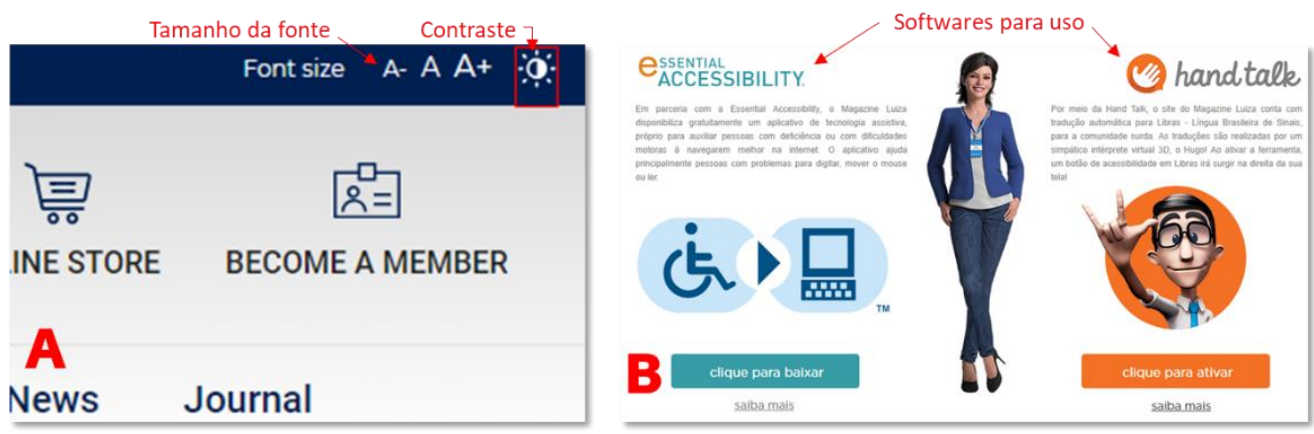

Aplicaçāo de libras

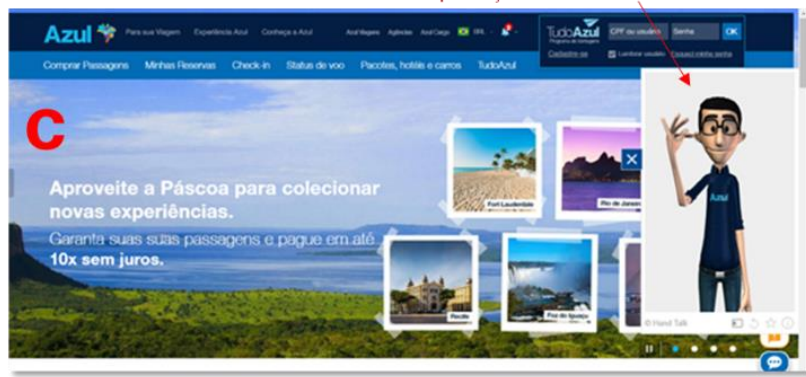

Opção Acessibilidade na página inicial que explica sobre as ferramentas disponiveis para uso
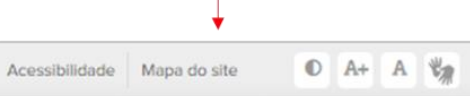

D

Para Web Content Accessibility Guidelines - WCAG (2019) a acessibilidade entorno do conteúdo da web deve atender a uma diversidade de questões que envolvem os sentidos visual, auditivo e físico, além da fala, da cognição, da linguagem, do aprendizado e de condições neurológicas. Segundo a WCAG (2019) as diretrizes para tornar o conteúdo da web

${ }^{5}$ Comitê de Ajudas Técnicas.

${ }^{6}$ Língua Brasileira de Sinais. 
mais acessível não atendem a todos os tipos, graus e combinações de deficiências, mas ainda assim a base das diretrizes é composta por quatro princípios fundamentais:

- Percebível - Os usuários devem ser capazes de perceber as informações apresentadas;

- Operável - Os usuários devem poder operar a interface (a interface não pode exigir interação que um usuário não pode executar);

- Compreensível - Os usuários devem ser capazes de entender as informações, bem como a operação da interface do usuário (o conteúdo ou a operação não pode estar além do seu entendimento);

- Robusto - O conteúdo deve ser robusto o suficiente para ser interpretado de forma confiável por uma ampla variedade de agentes do usuário, incluindo tecnologias assistivas.

Além das tecnologias assistivas, de diretrizes fundamentais, a The World Wide Web Consortium's - W3C (2019a) afirma que para se ter acessibilidade na web os sites precisam ser projetados para que as pessoas com deficiências percebam, entendam, naveguem e interagem com tais plataformas.

Partindo destes fundamentos, a organização INDCP (International Network on the Disability Creation Process), que promove respostas mais adequada às necessidades das pessoas com deficiências, incapacidades e situações incapacitantes da vida, desenvolveram o modelo HDMDCP (Human Development Model - Disability Creation Process) para explicar a criação da situação de deficiência. Durante a interação em situações de participação social ou ambiental podem ocorrer obstáculos, incapacidades e preconceitos que causam situações de desigualdade, ou seja, a deficiência não está na pessoa ${ }^{7}$ (INDCP, 2019). Com isso, a acessibilidade digital está vinculada com a estrutura feita na arquitetura da informação nos sites, bem como com as questões que envolvem o acesso, com a navegação e com organização do conteúdo informacional (Cusin \& Vidotti, 2009; Marsico \& Levialdi, 2004)

Dessa forma, a primeira questão a se enfrentar é sobre como avaliar a acessibilidade digital. A W3C (2019b) fornece uma lista com diversas ferramentas de avaliação de acessibilidade da $w_{e} b^{8}$. Segundo W3C (2019b), são programas que prestam serviços para identificar problemas de acessibilidades e que atendem às diretrizes formuladas pelos padrões internacionais. Porém, a W3C (2019b) alerta que, sozinhas, as ferramentas de avaliação não podem determinar se alguma plataforma atende ou não aos padrões de acessibilidade; recomenda-se, pois, avaliação humana bem informada.

A partir deste entendimento, perante o uso de avaliação automatizada e aplicada junto aos usuários, o pesquisador necessita de compreensão dos componentes específicos para definir a avaliação ou o que inspecionar durante a navegação em um site. Com base em Cybis, Betiol e Faust (2015) e Tidwell (2011) elencamos alguns componentes que podem ser utilizados:

- Objetos de interação: ajudam a navegar pelo site, encontrar informações e chegar aos objetivos, por exemplo: menus, botões, caixas de diálogo, etc.;

- Recursos audiovisuais: são representações criadas pelas relações entre imagens, elementos textuais, ícones, sons, animações, elementos esquemáticos, etc.

Além dos componentes, pode ser realizada avaliação heurística, como exemplo, diretrizes de usabilidade para tentar chegar a uma opinião sobre o que é bom ou ruim na interface. Um exemplo desta avaliação é encontrado em Molich e Nielsen (1990), que é composta desde informações irrelevantes até fornecer feedback apropriado dentro de um prazo razoável.

Direcionando esses componentes para acessibilidade digital, a W3C (2019c) explica que os desenvolvedores de site precisam de especificações técnicas para produzir conteúdo web acessível, o que inclui também o uso de tecnologias assistivas.

\footnotetext{
${ }^{7}$ Mas sim no sistema, serviço, produto e/ou contexto que não oferece condições e recursos adequados.

${ }^{8}$ Acesse "https://www.w3.org/WAl/ER/tools/"
} 
A WCAG (2019) elabora diretrizes de acessibilidade ao conteúdo da we $b^{9}$. Ela oferece uma forma dos desenvolvedores aplicarem as especificações técnicas corretas para produzir conteúdos acessíveis. Tais recomendações variam de acordo com os quatro princípios explicados anteriormente. Exemplos:

- Perceptível: a cor não é usada como o único meio visual de transmitir informações, indicando ações, solicitando respostas ou distinguindo elemento visual.

- Operável: toda funcionalidade do conteúdo é operável por meio de interface de teclado, sem exigir intervalos específicos para pressionamentos de teclas individuais.

- Compreensível: etiquetas ou instruções são fornecidas quando o conteúdo requer entrada do usuário.

- Robustez: os componentes da interface do usuário, no sentido de nome e função, podem ser determinados de forma programática.

\section{Método}

O método de coleta e avaliação desta pesquisa se dividiu em 5 etapas (ver Figura 3), divididas entre 2 ciclos (virtual e presencial). Inicialmente, no primeiro ciclo, buscamos artigos científicos que já tivessem se debruçado sobre a avaliação de sites orientados à compra de ingressos no Brasil, o que não foi encontrado; desta primeira busca, localizamos trabalhos diversos, no geral no campo da tecnologia da informação e computação, que apresentaram ferramentas dedicadas à aferir a acessibilidade de sites quanto aos recursos técnicos inerentes à linguagem de programação nas páginas avaliadas. Tendo em vista tal possibilidade, selecionamos três ferramentas automáticas de inspeção de acessibilidade (as ferramentas fornecem relatório de avaliação baseados nas Web Content Accessibility Guidelines). As três ferramentas automáticas são: ASES ${ }^{10}$; WAVE ${ }^{11}$ e Mada Web Accessibility Monitor for Qatar ${ }^{12}$. Essas três ferramentas foram testadas nos sites que integram nosso corpus de ação: Ingressos.com; Tickets For Fun; Ingresso Rápido e Blueticket.

\footnotetext{
${ }^{9}$ Acesse "https://www.w3.org/WAl/standards-guidelines/wcag/"

${ }^{10}$ Acesse "http://asesweb.governoeletronico.gov.br/ases/"

11 Acesse "wave accessibility toolbar for chrome

12 Acesse "http://qatar.checkers.eiii.eu
} 
Figura 3: Etapas de pesquisa.

\section{Etapas de pesquisa}

Ciclo 1 (virtual)

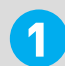

Busca de pesquisas científicas sobre acessibilidade em sites de

compras de ingressos

Identificação de sites orientados à avaliação de páginas quanto à acessibilidade
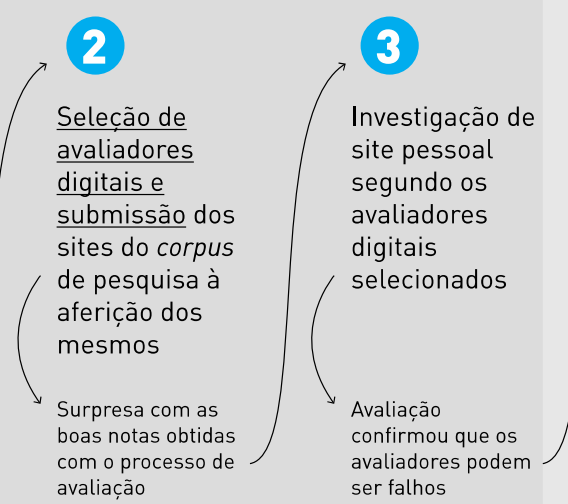

Investigação de site pessoal segundo os avaliadores digitais selecionados

ser fathos
Ciclo 2 (presencial)

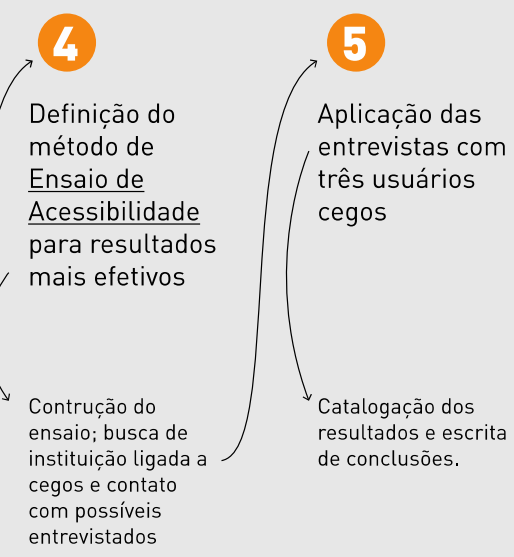

Os resultados da inspeção por ferramentas automáticas foram surpreendentes (ver Figura 4), uma vez que todos foram muito bem avaliados, considerando que a avaliação que atingiu o pior resultado obteve aproximadamente $70 \%$ da nota máxima nos avaliadores ${ }^{13}$. Nossa surpresa se deu, sobretudo, à hipótese que nos guiou a realizar esta pesquisa: a de que os sites de venda de ingressos seriam uma das barreiras enfrentadas por pessoas com deficiência visual na fruição de experiências de entretenimento e lazer.

Figura 4: Resultados da inspeção automática.

Resultados da inspeção por ferramentas automáticas

\begin{tabular}{|c|c|c|c|c|c|c|c|c|}
\hline \multirow{2}{*}{$\begin{array}{l}\text { Por erros } \\
\text { /barreiras }\end{array}$} & \multicolumn{2}{|c|}{ Blueticket } & \multicolumn{2}{|c|}{ Ingresso Rápido } & \multicolumn{2}{|c|}{ Ingressos.com } & \multicolumn{2}{|c|}{ Tickets For Fun } \\
\hline & $\begin{array}{l}\text { Inspecionado } \\
\text { /Quantidade }\end{array}$ & $\begin{array}{l}\text { Erros } \\
\text { /Barreiras }\end{array}$ & $\begin{array}{l}\text { Inspecionado } \\
\text { /Quantidade }\end{array}$ & $\begin{array}{l}\text { Erros } \\
\text { /Barreiras }\end{array}$ & $\begin{array}{l}\text { Inspecionado } \\
\text { /Quantidade }\end{array}$ & $\begin{array}{l}\text { Erros } \\
\text { /Barreiras }\end{array}$ & $\begin{array}{l}\text { Inspecionado } \\
\text { /Quantidade }\end{array}$ & $\begin{array}{l}\text { Erros } \\
\text { /Barreiras }\end{array}$ \\
\hline $\begin{array}{c}\text { ASES } \\
\text { (erros) }\end{array}$ & $?$ & 320 & $?$ & 3 & $?$ & 339 & $?$ & 0 \\
\hline $\begin{array}{l}\text { WAVE } \\
\text { (erros) }\end{array}$ & $?$ & 24 & $?$ & 140 & $?$ & 30 & $?$ & 1 \\
\hline $\begin{array}{c}\text { Mada } \\
\text { (barreiras) }\end{array}$ & 1903 & 112 & 1106 & 466 & 1614 & 344 & 492 & 16 \\
\hline \multicolumn{9}{|c|}{$\begin{array}{c}\text { Por } \\
\text { porcentagem }\end{array}$} \\
\hline ASES & \multicolumn{2}{|c|}{$72,47 \%$} & \multicolumn{2}{|c|}{$85,25 \%$} & \multicolumn{2}{|c|}{$73,39 \%$} & \multicolumn{2}{|c|}{$100 \%$} \\
\hline Mada & \multicolumn{2}{|c|}{$73,28 \%$} & \multicolumn{2}{|c|}{$69,47 \%$} & \multicolumn{2}{|c|}{$78,46 \%$} & \multicolumn{2}{|c|}{$98,39 \%$} \\
\hline
\end{tabular}

Uma vez que os resultados nos causaram surpresa, decidimos avaliar o site de um dos autores, a partir dos mesmos sistemas de avaliadores automáticos, já que o autor tem conhecimento sobre o processo de desenvolvimento de tal site, bem como da ausência de

${ }^{13}$ Apresentar a menor nota de cada site, e os gráficos e notas de todos. 
recursos acessíveis. Como resultado, verificamos que tal site obteve avaliação no Mada Web próxima aos $100 \%$ (percentual de nota máxima).

Tendo em vista o contexto, percebemos que os avaliadores automáticos selecionados poderiam apresentar resultados que não condizem com a realidade de acesso a informação e à realização de compras por parte dos usuários com severa deficiência visual; sendo tais avaliadores, portanto, inadequados para a aferição que buscamos neste trabalho. Desta conclusão, decidimos partir para uma próxima etapa de pesquisa: o desenvolvimento de um ensaio de acessibilidade, elaborado com base em Cybis, Betiol e Faust, 2015.

\section{Ensaio de acessibilidade}

Na segunda etapa do estudo, diante das incertezas por inspeção com ferramentas automáticas, foi realizada avaliação com usuários reais. No ensaio de acessibilidade, segundo Cybis, Betiol e Faust (2015, p. 420) "não há medição; o foco está nos aspectos qualitativos da experiência, nos comentários e nas sugestões". Para o ensaio de acessibilidade optou-se por amostragem não probabilista de tipicidade; foi procurado subgrupo típico definido por cegos com experiência em navegação web. A coleta de dados sucedeu-se através da observação e medidas de opiniões e de atitudes dos cegos durante a tarefa em simular a compra de ingressos online, denominada como ensaio de acessibilidade (Cybis, Betiol \& FUAT, 2015; Marconi \& Lakatos, 2018).

Concluído o escopo do ensaio, fomos a campo e entrevistamos três usuários cegos, com experiência no uso de ferramentas acessíveis para acesso de sites, aplicativos e demais plataformas e dispositivos digitais.

A escolha dos entrevistados se deu por indicação. Buscamos, inicialmente, alguma entidade que fosse referência na interação com pessoas cegas, ao que localizamos a ACIC Associação Catarinense para Integração do Cego, localizada em Florianópolis/SC. Realizamos, então, contato telefônico com a secretaria da instituição, quando apresentamos nosso projeto e solicitamos indicação de possíveis entrevistados. O primeiro deles, que é um dos professores responsáveis por integrar ao universo digital os atendidos pela instituição, nos indicou os outros dois. Aos três entrevistados, aplicamos o mesmo questionário de entrevista, individualmente, em local e horário escolhido por eles.

A seguir, detalhamos o ensaio de acessibilidade:

\section{Tipo de verbalização}

O processo contou com gravação em áudio do diálogo entre participantes (cegos) e pesquisador. Portanto, se trata de verbalização simultânea. Há um roteiro de tarefas a serem apresentadas pelo pesquisador. A gravação se inicia com a indicação do nome do entrevistado, do preenchimento dos itens que descrevem seu perfil e, em seguida, se indica o site que está sendo avaliado e as atividades a realizar. Ao fim do artigo, na sessão Anexos, é possível encontrar os roteiros de entrevista aplicados.

\section{Local de teste}

Os procedimentos aconteceram em locais que dispunham de tecnologias assistivas adequadas para a interação entre entrevistado e site, por meio de computador com acesso à internet. Todas as entrevistas tiveram local, data e horário definidos pelos entrevistados. O primeiro deles optou por realizar a entrevista em sua sala, na ACIC, com seu computador de mesa (que não tinha monitor, mas contava com caixas de som audível a ambos presentes), no período da tarde, durante seu turno de trabalho; a segunda entrevista foi realizada no prédio onde o entrevistado trabalha, em uma sala de reunião para duas pessoas, climatizada e com vedação acústica, à escolha do próprio, durante intervalo entre atividades, com utilização de notebook (a tela estava iluminada e podia ser vista pelo pesquisador, além de o som estar audível a ambos presentes); a terceira e última entrevista foi realizada na casa do entrevistado, com seu computador de mesa pessoal (monitor ligado mas com a utilização de fones de ouvido pelo 
entrevistado - inaudível ao entrevistador), à noite, após o expediente de trabalho do entrevistado.

\section{Gestão do constrangimento}

Por tratar de teste com característica de verbalização simultânea, o pesquisador acompanhou o entrevistado durante todo o processo, tentando não o interromper. Apenas buscando responder questões levantadas pelo entrevistado e questionando, a fim de um entendimento mais claro, dos caminhos e ações executadas pelo entrevistado. Sendo este o responsável por afirmar caso alguma tarefa não fosse possível de ser realizada. O pesquisador, contudo, perguntava os motivos que o entrevistado identificava como causas para a não execução de alguma tarefa, sempre buscando a problematização no sistema e nunca na condição do usuário.

\section{Definição da amostra de participantes}

Pessoas cegas com hábito de uso de computadores, smartphones e internet. Ocasionalmente, os três têm formação e trabalham no campo da Informática e Softwares, o que pôde nos dar segurança quanto à avaliação do corpus de pesquisa, sobretudo quando da afirmação de inacessibilidade das páginas avaliadas.

\section{Análise e Discussão dos resultados}

Apresentaremos a descrição dos entrevistados ${ }^{14}$ :

\section{Entrevistado 1:}

Michel, 30 anos, Ensino Médio, trabalha com informática e gosta de consertar computadores nas horas vagas. Nasceu com baixa visão e ficou cego aos 15. Já fez compras pela internet, sozinho e sua única preocupação, nessa experiência, era a de não receber o produto.

\section{Entrevistado 2:}

Renato, 24 anos, Ensino Superior Incompleto (Análise e Desenvolvimento de Sistemas), trabalha como testador de softwares e gosta de ser DJ nas horas vagas. Nasceu cego. Já fez compras pela internet, sem ajuda de terceiros e não encontrou grandes dificuldades.

\section{Entrevistado 3:}

Vítor, 27 anos, Ensino Superior (Técnico em Análise e Desenvolvimento de Sistemas), pósgraduando em Segurança da Informação. Trabalha como desenvolvedor de softwares e gosta de ler, nadar, conversar, sair, ver filmes e séries nas horas vagas. Ficou cego quando bebê, durante o período em que esteve na incubadora. Nunca fez compras pela internet, mas ajudou a mãe (que enxerga) a comprar um celular em site de compras.

Como resultado principal, concluímos que nenhum dos sites atendeu a todos os entrevistados nas diferentes tarefas que foram sugeridas. Entretanto, o site Tickets For Fun foi o único que possibilitou a simulação de compra por todos. É preciso pontuar que na primeira entrevista, este site não possibilitou a conclusão da compra devido ao sistema de confirmação de humano - o captcha ${ }^{15}$. Quando o entrevistado iria completar a ação, simulando a compra com cartão de crédito inexistente, o site propôs o desafio cognitivo, contudo a verificação era baseada em percepção visual, faculdade que impede o acesso de pessoas cegas. O sistema, contudo, ofereceu a opção de desafio via informação sonora. Entretanto, o conteúdo expresso era em inglês, o que significou barreira ao entrevistado.

Se verificou que os maiores problemas foram encontrados na hierarquização dos modos de compra, tais como na escolha de cartões de crédito, nas formas de pagamento, nos feedbacks

\footnotetext{
${ }^{14} \mathrm{~A}$ fim de preservar a identidade de nossos entrevistados, optamos por apresentá-los neste trabalho por nomes fictícios.

${ }^{15}$ Trata-se se desafio cognitivo utilizado por dispositivos digitais, visando diferenciar o usuário do sistema entre máquina ou humano.
} 
Autores no formato: Normandi, D. \& Schlemmer, A. | Vamos comprar ingressos: análise dos aspectos de acessibilidade para cegos em sites de venda de ingressos.

fornecidos pelos sistemas e, principalmente na seleção de assentos - em opções de entretenimento teatral e/ou auditórios. No site Tickets For Fun, que agradou a todos os entrevistados, as barreiras enfrentadas, por exemplo, foram percebidas nos retornos que o sistema oferecia no momento de compra. A de se destacar que nesta pesquisa apenas simulamos a compra, ou seja, já sabíamos que as informações de cartão para pagamento não seriam validadas. Contudo, caso estivéssemos em ocasião real de compra, possivelmente a ausência de feedback preciso sobre erros na digitação de dados no cartão poderiam resultar na desistência de realização da compra, por parte do usuário. Por isso, optamos por classificar as tarefas realizadas nessa página (Tickets For Fun) com o rótulo mostarda - interface restringiu tarefa (Figura 5). 
Autores no formato: Normandi, D. \& Schlemmer, A. | Vamos comprar ingressos: análise dos aspectos de acessibilidade para cegos em sites de venda de ingressos.

Figura 5: Relação de atividades e resultados obtidos.

\section{Mapa de atividades}

\begin{tabular}{|c|c|c|c|c|}
\hline Legenda: & $\begin{array}{ll}\text { Interface } & \text { Interface } \\
\text { permitic } & \text { restringiu } \\
\text { tarefa } & \text { tarefa }\end{array}$ & $\begin{array}{l}\text { Interfoce } \\
\text { blequeos } \\
\text { tarefa }\end{array}$ & & \\
\hline & Blueticket & Ingresso.com.br & Tickets For Fun & Ingresso Rápido \\
\hline \multirow[t]{2}{*}{ Tarefa 1} & $0 \quad 0$ & 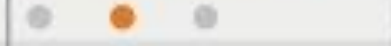 & & 00 \\
\hline & $\begin{array}{l}\text { Identificaçāo da regiāo nāo foi } \\
\text { täo clara mas permitiu o } \\
\text { entendimento / Houve } \\
\text { problemas de etiejetagem/ } \\
\text { Hierargula visual naso } 6 \\
\text { respeitada no fluxo para cegos }\end{array}$ & $\begin{array}{l}\text { Identificou outro estado } \\
\text { inicialmente / Para seleçáo de } \\
\text { estado correto, há a } \\
\text { necessidade de clicar em } \\
\text { cada opçāe, ao inwés de } \\
\text { navegar }\end{array}$ & & $\begin{array}{l}\text { Nāo apresentou possibitidade } \\
\text { de fittragem / Năo oferece } \\
\text { feedback ao clicar / 'Nāo } \\
\text { apresenta tiltragem de } \\
\text { cidades" }\end{array}$ \\
\hline \multirow[t]{2}{*}{ Tarefa 2} & 06 & 0 & 6 & $\theta$ \\
\hline & 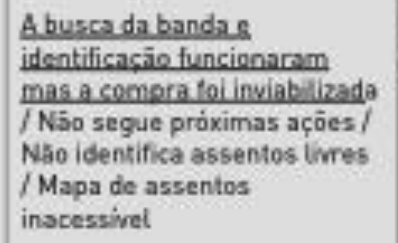 & $\begin{array}{l}\text { Obs: Ao selecionar modo do } \\
\text { filme [dublado, legendado ou } \\
\text { 30], e flucee năo prossegue }\end{array}$ & $\begin{array}{l}\text { Funçäo CAPTCHA bloqueou a } \\
\text { acesso de um entrevistado, } \\
\text { mas funcionou logo em } \\
\text { seguida / Näo informa, } \\
\text { antecipadamente, o número } \\
\text { de opçōes }\end{array}$ & $\begin{array}{l}\text { Assentos não sciecionàveis / } \\
0 \text { processo é barrado na } \\
\text { escolha de assentos / } \\
\text { Assentos não etiquetados }\end{array}$ \\
\hline \multirow[t]{2}{*}{ Tarefa 3} & 60 & 00 & e $\theta$ & 06 \\
\hline & $\begin{array}{l}\text { Nâ acessa categorias de } \\
\text { fütros /modalidades de } \\
\text { ingressos] / Nao identifica } \\
\text { assentos livres / Mapa de } \\
\text { assentos inacessivel/ } \\
\text { Problemas nos filtros / Naso } \\
\text { distingue entre assentos } \\
\text { livres ou ocupados / Nâ } \\
\text { apresenta feedback sobre } \\
\text { assento escolhido }\end{array}$ & $\begin{array}{l}\text { Botbes nà executaram } \\
\text { tarefas / A escolha de } \\
\text { assentos é inacessfvel / Popup } \\
\text { publicitśrio atrapalhou a } \\
\text { experiëncia / Assentos } \\
\text { clictrueis năo etiequetados" }\end{array}$ & $\begin{array}{l}\text { Naso há busca por periodo/ } \\
\text { Obs.: Ao inserir os dados } \\
\text { errados de cartâo } \\
\text { [simulaçãol, o sistema } \\
\text { reconhece o erro mas njo } \\
\text { identifica cem exatidàa ao } \\
\text { usuario }\end{array}$ & 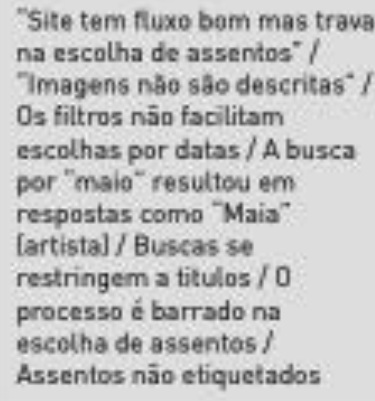 \\
\hline \multirow[t]{2}{*}{ Tarefa 4} & 00 & 0 & 0 & 6 \\
\hline & 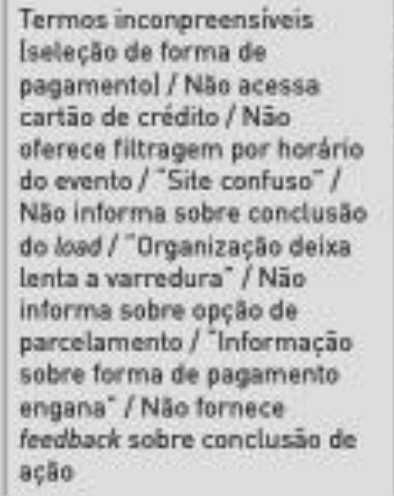 & $\begin{array}{l}\text { Popup publicitário surge e nāo } \\
\text { e interpretade pelo NvDA } \\
\text { (sistema de leitura de tela } \\
\text { utilizado\} }\end{array}$ & $\begin{array}{l}\text { Atividade realizada sem } \\
\text { bloquelos, porém e feedback } \\
\text { sobre a erro nas informaç̧es } \\
\text { do cartsa [simulação] é vago e } \\
\text { nảo surge no corpo da página }\end{array}$ & $\begin{array}{l}\text { Link home ficou inacessivel/ } \\
\text { Buscas se restringem a titulos } \\
\text { /0 processo } 6 \text { barrado na } \\
\text { escolha de assentos / } \\
\text { Assentes não etiquetados }\end{array}$ \\
\hline
\end{tabular}


Autores no formato: Normandi, D. \& Schlemmer, A. | Vamos comprar ingressos: análise dos aspectos de acessibilidade para cegos em sites de venda de ingressos.

A Figura 6 apresenta as principais considerações coletadas com os entrevistados durante as entrevistas. Importante notar como os comentários são alinhados entre si e não apresentam distorções significativas na avaliação que fazem dos sistemas:

Figura 6: Observações significativas dos entrevistados quanto aos sites investigados ao realizar as tarefas sugeridas.

\section{Mapa de observações}

\begin{tabular}{|c|c|c|c|c|}
\hline & Blueticket & Ingresso.com.br & Tickets For Fun & Ingresso Rápido \\
\hline Michel & $\begin{array}{l}\text { Nunca entrei nesse site antes. } \\
\text { O site não tem um } \\
\text { fluxograma. Não fica fácil } \\
\text { chegar em cada setor da } \\
\text { plateia. } \\
\text { Ferramenta de busca é muito } \\
\text { boa. Interessante pra quem } \\
\text { está programando. }\end{array}$ & $\begin{array}{l}\text { Não acessa escolha de } \\
\text { assentos. } \\
\text { Sinopse vem de imediato. } \\
\text { Os botões não executam } \\
\text { tarefas. }\end{array}$ & $\begin{array}{l}\text { Empacou no CAPTCHA. } \\
\text { Não aparece busca por } \\
\text { período. } \\
\text { Não tem o que reclamar. }\end{array}$ & $\begin{array}{l}0 \text { assento não é selecionável. } \\
\text { Esse diz o número de eventos } \\
\text { (no resultado de buscas). } \\
\text { Tem fluxo muito bom mas } \\
\text { trava na escolha de assentos. } \\
\text { As imagens não são descritas. }\end{array}$ \\
\hline$\underbrace{}_{\text {Renato }}$ & $\begin{array}{l}\text { Organização deixa lenta a } \\
\text { varredura, mas é acessivel. } \\
\text { Nunca comprei aqui. } \\
\text { Deixa ver o que está } \\
\text { acontecendo (sobre problema } \\
\text { inesperado) } \\
\text { Site confuso. } \\
\text { Não informa load. } \\
\text { Não tem feedback sobre } \\
\text { assento escolhido. }\end{array}$ & $\begin{array}{l}\text { Estrutura melhor que o do } \\
\text { Blueticket. } \\
\text { Tá melhor que o Blueticket: } \\
\text { filtrou a cidade. } \\
\text { Ao selecionar o modo filme, } \\
\text { sistema não prossegue. } \\
\text { Surge um Popup não } \\
\text { informado pelo NVDA }\end{array}$ & $\begin{array}{l}\text { Tá bem melhor esse aqui. } \\
\text { Porque estava logado no } \\
\text { Google, CAPTCHA deu legal. } \\
\text { Não informa load. } \\
\text { Caixa de combinação (elogiando a } \\
\text { solução para opção de parcelamento). }\end{array}$ & $\begin{array}{l}\text { O site aqui é muito ruim. } \\
\text { Link da busca não está } \\
\text { etiquetado. } \\
\text { Ruim a organização de } \\
\text { resultados. } \\
\text { Não permite alterar a cidade. } \\
\text { Não identifica assentos. Os } \\
\text { apresenta como "clicável". } \\
\text { O link home ficou inacessível. } \\
\text { A busca se restringe por } \\
\text { título. }\end{array}$ \\
\hline Vítor & $\begin{array}{l}\text { Tentar clicar e ver o que } \\
\text { acontece. } \\
\text { Navegar para conhecer. } \\
\text { Descreve as letras (sobre filira de } \\
\text { assentos). } \\
\text { Apareceu a mensagem 'Sem } \\
\text { ambiente configurado para } \\
\text { esse tipo de transação'(sobre } \\
\text { tentativa de parcelamento). } \\
\text { A informação sobre forma de } \\
\text { pagamento engana. } \\
\text { Não dá feedback sobre } \\
\text { conclusão da ação. }\end{array}$ & $\begin{array}{l}\text { Identificou Rio de Janeiro. } \\
\text { Assentos clicáveis não } \\
\text { etiquetados. } \\
\text { Popup publicitário atrapalha. }\end{array}$ & $\begin{array}{l}\text { Inicio conhecendo o site. } \\
\text { A cada clique, o site vai para o } \\
\text { menu, mas permite pular. } \\
\text { Tá bem acessível esse aqui. } \\
0 \text { site tem um pequeno bug. } \\
\text { Essa página tem muita } \\
\text { acessibilidade. }\end{array}$ & $\begin{array}{l}\text { Não dá feedback no clique. } \\
\text { Não permite navegar pelas } \\
\text { cidades. } \\
\text { Assentos com o mesmo } \\
\text { problema do 'ingresso.com.br'. }\end{array}$ \\
\hline
\end{tabular}

Anais do 9o Congresso Internacional de Design da Informação | CIDI 2019 
De acordo com o ensaio de acessibilidade realizado e fazendo-se uma avaliação a partir dos quatro princípios de acessibilidade estabelecido pela WCAG (ver item 2), consideramos que:

1. os sites investigados se mostram percebíveis, uma vez que as funções básicas de interação estiveram acessíveis aos comandos dos avaliadores humanos, por meio do uso de leitor de tela;

2. não alcançaram a condição de operável, já que embarreiraram a interação dos avaliadores humanos durante momentos decisivos no processo de compra, como no caso da seleção de assentos e consequente pagamento;

3. os sites avaliados se apresentaram compreensíveis, haja vista que mesmo quando embarreirados por algum procedimento com acessibilidade limitada, os participantes do ensaio conseguiram identificar as informações básicas;

4. por fim, o conteúdo tem robustez limitada, já que não propiciou a execução básica a que se propuseram: a venda de ingressos.

Verificamos que um grande obstáculo verificado pelos entrevistados, durante a avaliação dos sites de compras de ingresso, residiu na falta de interação adequada no momento em que o usuário necessita escolher o assento. Em todos os casos em que ocorreu a situação, o processo foi embarreirado. Assim, a simulação de compra foi interrompida, já que o pagamento só era acionado após a definição de assentos. Ademais, se identificou que a ausência de feedbacks decorrentes das ações dos avaliadores humanos dificultou/limitou (ver Figura 5) a interação com o sistema, sobretudo em momentos em que a segurança da informação precisa ser percebida, como no caso de pagamento. Destacamos que mesmo no site Tickets For Fun (que foi bastante elogiado), os retornos do sistema em relação aos dados incorretos de cartão foram insuficientes, já que a descrição dos erros não foram precisas.

É preciso, por fim, destacar que o termo acessibilidade, quando tratado no campo da Acessibilidade Digital tem significado mais restrito ao considerado neste trabalho, já que o entendimento se refere às condições adequadas de interação entre sistemas, máquinas onde os sistemas estão embarcados e usuários desses sistemas e máquinas, não se preocupando exatamente com as condições físicas e sensoriais dos usuários; já neste artigo, nossa avaliação está diretamente relacionada ao oferecimento de recursos adequados à interação por usuários cegos. Assim, por mais que os sites investigados contassem com estruturas aptas à acessibilidade por leitores de tela, a função básica que se espera de um serviço de vendas de ingresso não foi promovida, já que não foi possível a realização da compra de ingressos pelos entrevistados ${ }^{16}$.

\section{Considerações Finais}

Levantou-se questão sobre condições de acessibilidade e inclusão que sites de vendas de ingressos oferecem aos usuários com deficiência, uma vez que se percebe um movimento que aponta para a formalização de estratégias de inclusão desse público, seja por meio de iniciativas pontuais, seja pela necessidade de adequação configuradas por força de leis, tal como a Lei Brasileira da Inclusão (2016). Não objetivamos, assim, estudo propositivo, no sentido de estabelecer caminhos ou soluções a serem seguidos no universo digital, mas sim avaliar como importantes ferramentas utilizadas para vendas de ingressos lidam atualmente com o público com deficiência visual e como estas pessoas avaliam suas experiências frente à necessidade/desejo de se incluir numa sociedade cada vez mais dependente dos serviços oferecidos no universo digital e virtual. Contudo, acreditamos que este trabalho possa servir como referência para vislumbrar abordagens mais qualitativas e propositivas quanto à

\footnotetext{
${ }^{16}$ Excluindo-se as simulações de sucesso no site Tickets For Fun.
} 
acessibilidade de dispositivos e ferramentas digitais em relação a pessoas com severa deficiência visual.

Sobre os recursos de avaliação utilizados, sentimos falta de padronização de ferramentas úteis para analisar aspectos da interface não dirigidas apenas para especialistas. Já a respeito dos métodos de investigação utilizados, o fator limitador por inspeção de ferramentas automáticas foi registrado por W3C (2019b) e Cybis, Betiol e Faust (2015). Por isso, como complemento, foi selecionado a avaliação humana, realizada por ensaio de acessibilidade com usuários reais, o que nos apresentou resultados mais bem qualificados.

Em consenso com estudos de Guimarães e De Sousa (2015); Reinaldi, De Camargo Júnior e Calazans (2011) e Ferreira, Da Silveira, Nunes e Da Cunha Lima (2010), a acessibilidade digital em conteúdo web não contempla as reais necessidades dos cegos. Existe indicação de ausência de ações para melhorar a segurança e autonomia durante a navegação pelos sites utilizados neste estudo. As TA's precisam ser incluídas, melhoradas e projetas para as necessidades reais dos cegos e não apenas atender alguns itens de uma norma, pois a percepção, o ser operável, a compreensão e a robustez são elementos essenciais para a acessibilidade digital.

\section{Agradecimentos}

Agradecemos à Fundação de Amparo à Pesquisa do Estado de São Paulo (FAPESP) pelo apoio e financiamento a essa pesquisa, realizado por meio do protocolo $2017 / 13180-8^{17}$.

\section{Referências}

ASES (Avaliador e Simulador de Acessibilidade em Sítios). Portal do Software Público Brasileiro - Ministério do Planejamento, Desenvolvimento e Gestão - ASES. Disponível em: <https://softwarepublico.gov.br/social/ases> Acesso em: 25 mar. 2019.

Brasil. LEI No 13.146, DE 6 DE JULHO DE 2015 (2015). Lei Brasileira de Inclusão da Pessoa com Deficiência (Estatuto da Pessoa com Deficiência). Disponível em: <http://www.planalto.gov.br/ccivil_03/_Ato2015-2018/2015/Lei/L13146.htm>. Acesso em: 25 mar. 2019.

CAT - Comitê de Ajudas Técnicas. Conceito de Tecnologia Assistiva apresentado pela Comissão. Ata da VII Reunião do Comitê de Ajudas Técnicas CAT/CORDE/SEDH/PR. Realizado em: 13 e 14 de dez 2007. Disponível em:< http://www.assistiva.com.br/Ata_VII_Reuni\%C3\%A3o_do_Comite_de_Ajudas_T\%C3\% A9cnicas.pdf >. Acesso em 01 jul 2019.

Censo Demográfico. (2011). Características da população e dos domicílios: resultados do universo. Rio de Janeiro: IBGE. Disponível em: <http://www.censo2010.ibge.gov.br/>. Acesso em: 7 de jul. 2019.

Cusin, C. A. \& Vidotti, S. A. B. G. (2015). Inclusão digital via acessibilidade web. Liinc em Revista, v.5, n.1, março, 2009, p. 45 - 65.

Cybis, W., Betiol, A. H., \& Faust, R. Ergonomia e Usabilidade - Conhecimentos, Métodos e Aplicações. $3^{a}$ Edição. São Paulo: Novatec.

Marsico, M. \& Levialdi, S. (2004). Evaluating web sites: exploiting user's expectations. International Journal of Human-Computer Studies. Volume 60, p. 381-416.

\footnotetext{
17 "As opiniões, hipóteses e conclusões ou recomendações expressas neste material são de responsabilidade do(s) autor(es) e não necessariamente refletem a visão da FAPESP"
} 
Autores no formato: Normandi, D. \& Schlemmer, A. | Vamos comprar ingressos: análise dos aspectos de acessibilidade para cegos em sites de venda de ingressos.

Ferreira, S. B. L., Silveira, D. S., Nunes, R. R., \& LIMA, C. S. P. C. (2010). Avaliando Acessibilidade em Sistemas de Comunicação com Usuários Cegos. iSys - Revista Brasileira de Sistemas de Informação. v. 3.

Guimarães, Í. J. B. \& Souza, M. R. F. (2015). Acessibilidade em websites de comércio eletrônico: avaliação através da interação com usuários cegos na Paraíba. Pesq. Bras. em Ci. da Inf. e Bib., João Pessoa, v. 10, n. 1, p. 185-197.

Marconi, A. M. D. \& Lakatos, M., E. Técnicas de Pesquisa (2018). $8^{a}$ edição. São Paulo: Atlas.

Molich, R. \& Nielsen, J. (1990). Improving a human-computer dialogue. Communications of the ACM. Vol. 33 Issue 3, Março, p. 338-348.

José, N. K. (2006). Olho no olho: campanha nacional de prevenção à cegueira e reabilitação visual do escolar. Rio de Janeiro: Cultura Médica; São Paulo: CBO.

Reinaldi, L. R., Camargo Jr., C. R., \& Calazans, A. T. S. (2011). Acessibilidade para pessoas com deficiência visual como fator de inclusão digital. Univ. Gestão e TI, Brasília, v. 1, n. 2, p.35-61, jul./dez.

Schwab, K. (2016). A quarta revolução industrial. São Paulo: Edipro.

Tidwell, J. Designing Interfaces (2011). 2a . ed. Sebastopol: O'Reilly Media, Inc.

Vivarta, V. (2003). Mídia e deficiência. Brasília: Andi; Fundação Banco do Brasil.

WCAG (Web Content Accessibility Guidelines). W3C Recommendation 05 June 2018. Disponível em:<https://www.w3.org/TR/2018/REC-WCAG21-20180605/> Acesso em: 25 mar. 2019.

WebAIM (Web Accessibility In Mind). WAVE Browser Extensions. Disponivel em: <http://wave.webaim.org/extension/>. Acesso em: 25 mar. 2019.

W3C - THE WORLD WIDE WEB CONSORTIUM'S (a). Introduction to Web Accessibility. Disponível em: <https://www.w3.org/WAl/fundamentals/accessibility-intro/\#what>. Acesso em: 01 jul. 2019.

W3C - THE WORLD WIDE WEB CONSORTIUM'S (b). Evaluating Web Accessibility Overview. Disponível em: < https://www.w3.org/WAl/test-evaluate/>. Acesso em: 01 jul. 2019.

W3C - THE WORLD WIDE WEB CONSORTIUM'S (c). Essential Components of Web Accessibility. Disponível em: < https://www.w3.org/WAl/fundamentals/components/>. Acesso em: 01 jul. 2019.

\section{Sobre o(a/s) autor(a/es)}

Diego Normandi, Mestre, USP, Brasil, diegonmd@usp.br

André Schlemmer, Mestre, UFPR, Brasil, schlemmer.andre@gmail.com 
Autores no formato: Normandi, D. \& Schlemmer, A. | Vamos comprar ingressos: análise dos aspectos de acessibilidade para cegos em sites de venda de ingressos.

\section{Anexos}

Entrevista ( ) (perguntar se a cegueira é congênita ou adquirida)

Nome

Idade

Profissão

O que faz nas horas de lazer?

Com que frequência você usa dispositivos digitais e internet?

Cego congênito ou adquirido?

Já fez alguma compra pela internet? ( ) Sim | （） Não

\section{Se SIM}

Em que site? Fez sozinho?

Como foi a experiência?

\section{Se NÃO}

Por que não?

\section{Blueticket}

1. Identifique a região do Brasil onde você está (LINK NÃO FUNCIONOU COMIGO)

2. Haverá um show da banda TAL, simule a compra do ingresso (meia-entrada) por meio de cartão de crédito Visa.

3. Em maio, você está o mês todo de férias, procure uma peça teatral que lhe desperte o interesse e simule a compra de um ingresso (meia-entrada). A escolha de assentos é de sua livre escolha.

4. Você só consegue ir a shows que iniciem a partir das 21 horas. Por favor, escolha um que atenda à esta condição e simule a compra do ingresso por meio de cartão ELO, parcelado em 3 vezes. Escolha um lugar que fique o mais próximo ao palco possível.

Sobre o site que você avaliou, sugere alguma melhoria? 


\section{Ingressos.com}

1. Identifique se a região do país apresentada condiz com a sua. Se não, troque pela cidade onde você está.

2. Há um filme em cartaz que você quer conhecer: Capitã Marvel. Por favor, veja os horários disponíveis e os locais de exibição e selecione qual deles é mais interessante pra você.

3. O filme Shazam está em cartaz no Floripa Shopping, na sala 6 , às 21:30, com dublagem. Por favor, simule a compra de duas meias, com cartão Mastercard. Fique livre para escolher os assentos que desejar. Caso deseje comprar pipoca e refrigerantes, escolha-os livremente.

4. Você só consegue ir a filmes que iniciem a partir das 21 horas. Por favor, escolha um que atenda à esta condição e simule a compra do ingresso.

Sobre o site que você avaliou, sugere alguma melhoria?

\section{Tickets for fun}

1. Haverá um show da banda TAL, simule a compra do ingresso (meia-entrada) por meio de cartão de crédito Visa.

2. Em maio, você está o mês todo de férias, procure uma peça teatral que the desperte o interesse e simule a compra de um ingresso (meia-entrada). A escolha de assentos é de sua livre escolha.

3. Você só consegue ir a shows que iniciem a partir das 21 horas. Por favor, escolha um que atenda à esta condição e simule a compra do ingresso por meio de cartão ELO, parcelado em 3 vezes. Escolha um lugar que fique o mais próximo ao palco possível.

Sobre o site que você avaliou, sugere alguma melhoria?

\section{Ingresso rápido}

1. Identifique a região do Brasil onde você está

2. Haverá um show da banda TAL, simule a compra do ingresso (meia-entrada) por meio de cartão de crédito Visa.

3. Em maio, você está o mês todo de férias, procure uma peça teatral que the desperte o interesse e simule a compra de um ingresso (meia-entrada). A escolha de assentos é 
Autores no formato: Normandi, D. \& Schlemmer, A. | Vamos comprar ingressos: análise dos aspectos de acessibilidade para cegos em sites de venda de ingressos.

de sua livre escolha.

4. Você só consegue ir a shows que iniciem a partir das 21 horas. Por favor, escolha um que atenda à esta condição e simule a compra do ingresso por meio de cartão ELO, parcelado em 3 vezes. Escolha um lugar que fique o mais próximo ao palco possível.

Sobre o site que você avaliou, sugere alguma melhoria?

Sobre o site que você avaliou Sugere alguma melhoria? 